\title{
Determinants of public support for eco-social policies: A comparative theoretical framework
}

Dimitri Gugushvili, Adeline Otto (KU Leuven)

\begin{abstract}
Global warming and some climate change policies pose additional social risks that necessitate novel responses from the welfare state. Eco-social policies have significant potential to address these challenges, but their wide-scale adoption will depend, among other factors, on public support. In the current article, we theorise how public opinion about eco-social policies is likely to be influenced by a set of contextual and individual-level factors, as well as the perceived welfare deservingness of the target groups. Alongside contributing to the emerging body of literature on eco-social policies, this theoretical framework could help policymakers to anticipate the social groups that will support or oppose eco-social policy agendas and how some of the contradictions could be reduced through policy design.
\end{abstract}

\section{Keywords}

Eco-social policies, public opinion, welfare state, climate change, global warming

\section{Introduction}

Climate change is undoubtedly one of the main challenges of the twenty-first century, triggering unprecedented threats to physical and mental health, public welfare and economic development for current and future generations. Multiple approaches to tackling the issue 
have been discussed and implemented, including policies that seek to adapt to, slow the growth of or reduce greenhouse gas emissions as one of the main drivers of climate change (IPCC 2014). Although effective from an ecological point of view, some of these policies are expected to disproportionally affect vulnerable and poor people (Markkanen \& Anger-Kraavi 2019; Zachmann et al. 2018), thus posing additional challenges to the welfare state.

Mindful of this hazard, a number of scholars argue that the transition to carbon-neutral societies will need to be accompanied by strengthened traditional social policies, as well as so-called eco-social policies that aim to reconcile ecological and welfare objectives (Degryse and Pochet, 2009; Gough, 2013, 2017; Koch and Mont, 2016, Meadowcroft, 2008; Jakobsson et al., 2018). Despite the double advantage of eco-social policies, it would be naïve to expect that their introduction on a massive scale will be met with unanimous public support, even in most of the developed countries (Fritz \& Koch 2019). Instead, we anticipate that a substantive eco-social policy agenda is bound to reinvigorate and add extra controversy to the longstanding societal and political debate on what risks should be socialised, who should be covered and why.

Our aim in the present article is to develop a comparative theoretical framework that can help us understand the drivers of cleavages in people's attitudes towards eco-social policies and the ways to mitigate these controversies through policy design. In doing so, we build primarily on insights from welfare attitudes literature. We acknowledge, however, that these theoretical approaches have been developed and tested on the basis of income support benefits and services targeted at groups experiencing traditional social risks, such as old age, sickness and unemployment. These social risks are easily verifiable and clearly concentrated within specific social groups. In addition, the wider public has coherent (although competing) ideas about how non-biological social risks relate to individual behaviour. For example, some 
people view unemployment as inevitable in a market economy, whereas others believe it is caused by a lack of self-discipline and motivation. By contrast, the new risks triggered by climate change and some environmental policies are more diffuse, less visible in the shortterm, multi-faceted and complex (Gough, 2008; Schaffrin, 2014; Koch and Fritz, 2014). There is also less public awareness about the social effects of environmental problems as compared with traditional social risks. By taking into account these differences and explaining their repercussions for public support, our framework contributes to the emerging body of literature on eco-social policies. In addition, our insights may have substantial practical value, as they could help policymakers to anticipate what their potential support base is and who their likely opponents will be when designing eco-social measures, as well as how some of these divisions can be narrowed.

The article is structured as follows: in the next section, we discuss the direct and indirect social risks resulting from climate change, and the groups that are likely to be most exposed to these risks. We also define what eco-social policies comprise with regard to offering a way of addressing these risks. We then present our arguments concerning how contextual and individual-level factors can be expected to shape mass attitudes towards eco-social policies. In the final section, we summarise our framework and discuss avenues and methods for future research.

\section{Climate change related social risks and eco-social policies}

In conjunction with redistributing incomes and life chances, stimulating economic efficiency, and enhancing people's human and social capabilities, the management of social risks is the fundamental task of the welfare state (Esping-Andersen, 1990; Gough, 2008, 2017). In this 
context, social risks are understood as a structural and exogenous challenge or transformation, causing problems that prompt institutions and/or individuals to develop or alter their risk management strategies. Old age, sickness, work injury and unemployment are considered traditional or first-generation social risks, which emerged after industrialisation and urbanisation processes in Western economies in the nineteenth and twentieth centuries. 'New social risks', or second-generation social risks, result from post-WWII developments such as deindustrialisation, globalisation, changing demographic structures and the proliferation of non-standard employment patterns. They refer to the challenges of having to balance paid work and family responsibilities (especially childcare), and becoming frail while lacking family support. With regard to employment, the challenges include lacking the skills necessary to gain access to an adequately paid and secure job, and having skills and training that become obsolete while being unable to upgrade them through lifelong learning (TaylorGooby, 2004; Bonoli, 2005, 2007).

With regard to climate change, Johansson and colleagues (2016: 96-97) suggest that the issue might require the reconceptualisation of social risks in a manner that goes beyond the workwelfare nexus and the post-industrial welfare state'. Depending on the projected rise in global temperature and the location, the direct risks from climate change include floods, droughts, heavy storms and rainfall, heatwaves, water stress, wildfires and deforestation. They risk affecting people's living and working environment, their employment and economic security, and their health (for example malnutrition, diarrhoeal and infectious diseases, and cardiorespiratory diseases). Low-income groups experience the greatest likelihood or predisposition to be adversely affected, while having less ability to respond adequately (IPCC, 2014; Gough, 2017). Further potential effects of these risks include distress migration and displacement (Martin, 2010; Opitz Stapleton et al., 2017; Boas et al., 2019). 
In addition, some of the policies addressing global warming generate indirect social risks. On the one hand, climate policies produce immediate costs that may potentially absorb some of the resources allocated for social policies (Gough et al. 2008; Schaffrin 2014). Climate policies are also likely to have an adverse influence on economic growth, which is currently the prevailing mechanism to fund welfare (Büchs \& Koch 2017). On the other hand, climate policies can extend or intensify social inequalities, depending on the distribution of their costs across different social groups. For example, concerted efforts expended on the transition to clean energy production will inevitably lead to mass layoffs in fossil fuel industries, disproportionately affecting workers with limited transferable skills and damaging the communities built around these industries (Chomsky \& Pollin 2020).

Many scholars also warn about the regressive effects that various climate policies may entail in addition to destroying jobs in specific industries (Serret and Johnstone, 2006; Pye et al., 2008; Söderholm and Pettersson, 2008; Büchs et al., 2011; Schaffrin, 2013; Gough, 2013, 2017; Zachmann et al., 2018; Markkanen and Anger-Kraavi, 2019; Dryzek, 2008; Jakobsson et al., 2018). These researchers point out that the groups most affected by - but least responsible for - global warming may pay disproportionally more for the reduction of emissions through higher energy bills, or could contribute a disproportionally high proportion of their income to the financing of climate change adaptation or mitigation policies (for example carbon taxes, the subsidised retro-fitting of private homes and the installation of solar panels). In the context of what can be termed 'third generation eco-social risks', some authors even mention eco-exclusion or a new eco-poverty (Fitzpatrick 2011). This describes a situation marked by inadequate resources and opportunities, limited purchasing power, poor communal facilities, higher levels of poor health and lower rates of insurance coverage, as well as the risk of not being able to pay (higher) fuel bills, invest in the retrofitting of houses 
or a more fuel-efficient car, or to afford other costs related to extreme weather changes or regressive climate policies. It is nevertheless important to note that the risks stemming from global warming are not limited to low-income groups; they can also adversely affect people on middle incomes, especially those exposed to traditional social risks and those employed in fossil fuel industries.

Acknowledging the challenges of eco-social risks, several scholars have called for the strengthening of traditional social protection mechanisms, as well as for the introduction of new eco-social policies (Gough, 2013; Koch and Fritz, 2014; Meadowcroft, 2008). To date, a precise definition of eco-social policies remains lacking, although numerous measures for advancing the eco-social agenda have been proposed. These include support for the retrofitting of energy-efficient housing improvements, $\mathrm{CO}_{2}$-neutral social housing, support for small-scale energy cooperatives, social employment in the circular economy, quality public transport infrastructure in less affluent neighbourhoods, a (social) climate tax shift, taxing high-carbon luxuries, social or rising block tariffs, smart metering and energy saving advice for low-income households, to name just a few. More radical proposals, which are usually associated with the degrowth/post-growth movement, include the introduction of minimum income guarantees, caps on maximum income and wealth, the reduction of working hours to facilitate more equal distribution of employment opportunities, and the reduction of labour taxes at the expense of higher carbon taxes (Büchs \& Koch 2017; Kallis 2011).

In our opinion, to qualify as an eco-social measure, a public policy has to target individuals and/or households (as opposed to industries or technological innovations) and have two simultaneous objectives: to improve the ecological situation and to do so in a way that redistributes resources from upper to lower and middle-income groups. The second component is what distinguishes eco-social measures from general environmental policies, 
and it requires a careful assessment of how the benefits (or costs) are spread across income groups. In some cases, this can be relatively straightforward. For example, insulation subsidies for low-income families or insulating social housing are progressive by default. Conversely, subsidies for installing solar panels are regressive: despite being available to everyone, their take-up depends on a household's finances and in practice it is upper-middle and high-income families that benefit the most. It is nevertheless important to stress that eco-social policies do not have to be targeted at specific disadvantaged groups. Universal measures can also be redistributive if they are financed through progressive taxation and if the utilisation of benefits does not depend on a households' financial means. For example, a policy involving the distribution of free solar panels to every household will be a progressive measure, as long as the country's taxation system is progressive.

\section{Determinants of attitudes towards eco-social policies}

\section{Contextual determinants}

Since the country context determines both the need for eco-social policies and the capacity to implement them, we argue that public opinion about these measures is bound to be influenced by structural and institutional factors. The first crucial factor is a country's affluence, as this has been systematically found to be correlated with both welfare and environmental attitudes. However, in both areas there are contradicting theoretical mechanisms through which a country's affluence could lead to a more or a less accommodating attitude. On the one hand, it is proposed that when countries are affluent, environmental protection is more affordable, and people are thus more supportive of ecological policies (Diekmann \& Franzen 1999; Franzen \& Meyer 2010). It is also no 
coincidence that the most advanced welfare states exist in the richest countries. On the other hand, it has also been pointed out that the transition to economies that are more eco-friendly will incur higher costs in more-affluent countries, reducing the general willingness to pay for the change (Gelissen 2007). Similarly, it is argued that because ecological problems are more severe in economically less developed countries, public support for environmental measures is stronger (Dunlap \& Mertig 1995). Some scholars also suggest that because rich countries provide more employment opportunities, people there tend to be less supportive of public welfare provision and income redistribution (Blekesaune 2007; Dallinger 2010). Each of these theories is supported by some empirical evidence. The most relevant findings are nevertheless provided by studies into attitudes towards degrowth, as conceptually there is a significant overlap between eco-social policies and the idea of degrowth. In fact degrowth, understood as 'equitable downscaling of production and consumption that increases human well-being and enhances ecological conditions at the local and global level, in the short and long term' (Schneider et al., 2010: 512), is argued to be impossible without solid eco-social measures (Bohnenberger \& Koch 2020; Büchs \& Koch 2017). In this regard, the evidence is relatively coherent: higher GDP per capita is associated with greater support for degrowth (Brechin \& Kempton 1994; Dunlap \& Mertig 1995; Gerhards \& Lengfeld 2008; Gugushvili 2021). Accordingly, we propose that support for eco-social policies will be higher in moreaffluent countries, because a stronger economic base makes these measures more affordable than in less wealthy countries. Nevertheless, even at similar levels of economic development, exposure to climate change related risks varies considerably. For example, in Europe, Mediterranean countries are expected to be far worse affected than Scandinavian ones because of geographical factors. Intuitively, our expectation is therefore that support for ecosocial policies will be higher in countries more exposed to climate change related hazards. 
Another crucial factor is the extent of poverty and inequality in a given context. In this case also, two opposing causal mechanisms are discussed in relevant literature. On the one hand, high levels of poverty and inequality are argued to generate demand for more redistribution for two reasons. First, the greater the extent of these problems, the more visible they are to society. Second, in more unequal contexts, there are a greater number of people with a rational interest in income redistribution (Meltzer and Richard, 1981). On the other hand, the levels of poverty and inequality may be high in some contexts because people in these countries are more individualistic and suspicious of government-induced redistribution of income. The empirical evidence is more in favour of the first mechanism. Most cross-national studies find a positive correlation between income inequality and demand for redistribution (Dallinger 2010; Finseraas 2009; Jaeger 2013). In line with these findings, our expectation is that support for eco-social policies will be higher in more unequal countries.

Theorising the effects of welfare institutions on support for eco-social policies is more challenging. Meadowcroft's (2008: 331-332) observation that 'at present there is no elegant typology of environmental states equivalent to the well-known classification of welfare states' continues to be valid after more than a decade. Therefore it is hard to ascertain the extent to which the two types of regimes overlap. In this regard, valuable evidence has been provided by a few recent studies. A comparative analysis of 30 developed countries by Koch and Fritz (2014) showed that there is hardly any link between welfare regimes and environmental outcomes. The authors also did not find stronger support for a set of environmental measures in Nordic countries than in other welfare regime types. Similarly, in a study using three waves of ISSP data for 14 countries, Jakobsson and colleagues (2018) found no country-level (or individual-level) correlation between support for income redistribution and the willingness to pay for environmental protection. These findings cast 
doubt on Dryzek's (2008) theory that coordinated market economies with social-democratic welfare regimes are best placed to address the social challenges posed by climate change. However, two recent studies applying different methods to the same data for 23 European countries, found that simultaneous support for environmental and social policy measures was higher in Nordic countries than in most other European nations (Fritz \& Koch 2019; Otto \& Gugushvili 2020).

Accordingly, it would be premature to dismiss the importance of welfare regimes in shaping opinions about eco-social policies based on relatively scant evidence. In our opinion, at least two dimensions of welfare regimes are important in this respect: the dominant principle of distributive justice (equality, equity or need) and the extent of state intervention in welfare provision (comprehensive versus marginal). Thus, the scope of specific eco-social measures will also matter. Policies targeted more narrowly at low-income groups are likely to be more popular in liberal regimes than in social-democratic ones, given the former's residual and need-based nature. Conversely, eco-social policies that cover both low and middle-income groups will be more popular in Nordic regimes, where many benefits are universal and equality based. Since the equity principle is the least compatible with the concept of vertical redistribution, our expectation is that - all other things being equal - people in conservative welfare regimes will be the least supportive of eco-social measures. Similarly, where the public is accustomed to less intensive government involvement in welfare provision, as in the USA, enthusiasm for eco-social policies will be lower.

Individual-level determinants 
Despite the importance of contextual factors, it is well-established that most of the variation in welfare and environmental attitudes occurs at the individual level (Dallinger 2010; Gelissen 2007; Harring 2013; Roosma et al. 2016); with self-interest, ideology and perceived welfare deservingness being particularly important factors. We expect the same to be true in relation to opinions about eco-social policies.

\section{Self-interest}

In theorising the effects of self-interest on support for eco-social policies, it is important to acknowledge that the social base of support differs between welfare policies and ecological policies. Welfare attitudes literature provides clear and consistent evidence that disadvantaged groups have a rational interest in public welfare provision, as they benefit from redistribution (Blekesaune \& Quadagno 2003; Busemeyer \& Neimanns 2017; Fraile \& Ferrer 2005; Hasenfeld \& Rafferty 1989; Jæger 2006; Svallfors 1997). With regard to environmental measures, the opposite appears to apply: multiple studies have shown that ecological concerns and policies find stronger support among the better-off groups in society (Chaisty \& Whitefield 2015; Fairbrother 2013; Gelissen 2007; Harring 2013; Marquart-Pyatt 2012). There are at least two reasons for this. First, a safe environment is not only for the public good but is also a personal benefit, for which the demand increases once more basic needs (such as food and shelter) have been satisfied (Franzen \& Meyer 2010). Second, a higher income also strongly correlates with higher educational qualifications, which in turn increases the awareness of ecological hazards (Tjernström and Tietenberg, 2008; Poortinga et al., 2019) and also potentially fosters a greater commitment to the common good (Gelissen 2007). In recent literature, this double cleavage in welfare and environmental preferences across income groups has been highlighted in the eco-social divides theory (Otto \& Gugushvili 2020). 
In fact, one of the primary justifications for eco-social policies is that they can be an effective means to bridge these divides. However, the endorsement of eco-social policies by the traditional support base of welfare states will depend on at least three aspects. First, whether these policies will complement existing social policies or will be used as an alternative, for example subsidies for retro-fitting houses at the expense of reduced social cash transfers. If there is no trade-off, the traditional clientele of the welfare state has no reason to oppose eco-social measures, as they can only benefit from them. In other cases, however, they (especially the low-income beneficiaries of social transfers) could be expected to prefer traditional methods of financial support to address their immediate needs. Second, the extent to which these policies will be seen as a direct threat to jobs in polluting industries. By reducing carbon emissions, any eco-social measure is obviously bad for fossil fuel businesses. The effects of some policies are nevertheless more visible than those of others, because they are more concentrated and more immediate. For example, a carbon tax has the potential to destroy many jobs in specific industries in the short term, even if all the generated revenues are used for well-targeted or universal social transfers. Hence, it is very likely that people employed in fossil fuel production and distribution will oppose such measures, irrespective of their income. Retrofitting houses also reduces the demand for heating, but unlike the introduction of a carbon tax, it will take a number of years before a large portion of a country's housing stock is brought up to modern standards of thermo-isolation. Hence, the job losses in the affected sectors will be more gradual and less visible. Third, the extent to which policymakers and climate activists succeed in conveying the message to less-affluent groups that they are very likely to be the primary victims of environmental hazards and that these risks are already materialising, for example through excess death rates in polluted, lowincome neighbourhoods. 


\section{Ideology}

In contrast to self-interest, the direction of the effect of ideology for the support of social and environmental policies is similar. Supporters of public welfare and climate policies are more likely to be on the left of the political spectrum, as they perceive both public interventions as necessary to correct the wrongdoings of the market economy (Blekesaune \& Quadagno 2003; Carlsson et al. 2010; Fraile \& Ferrer 2005; Hasenfeld \& Rafferty 1989; Kvaløy et al. 2012; McCright et al. 2016). By contrast, people with a right-wing ideology are usually opposed to public welfare provision on the grounds of alleged market distortion, adverse incentives, infringement of individual freedoms and so on (see e.g. Murray, 1984). At the same time, conservative ideology is also strongly correlated with scepticism about (not to say denial of) climate change and its causes (McCright et al. 2016; Mccright \& Dunlap 2011). In some extreme cases such as the USA, conservative politicians even portray the climate change agenda as a smokescreen for advancing radical left-wing ideas. We expect that, unlike the self-interest cleavage, eco-social policies will deepen ideological divides by increasing the stakes for both ideological camps: for those with a left-wing ideology, the policies will be essential for achieving not only social, but also environmental and inter-generational justice; for right-wing people, the policies will not just be about misallocating resources from the hard-working to the idle, but also spending them on something that is not needed and thus even more wasteful than traditional social transfers.

\section{$\underline{\text { Welfare deservingness }}$}

Welfare attitudes literature identifies five determinants of welfare deservingness - control, attitudes, reciprocity, identity and need - that influence public support for specific social 
policies (van Oorschot 2006; van Oorschot \& Roosma 2017). However, the qualitative differences between eco-social and traditional risks also necessitate reconsidering these criteria in relation to the beneficiaries of eco-social policies. In the context of traditional social risks, the need criterion implies a lack of resources (financial and/or other) to achieve a socially acceptable minimum standard of living. However, in the context of eco-social risks, need can be understood in two distinctive ways. First, as the inability to meet the extra costs caused by global warming and some climate policies. Second, as the extra costs consuming an excessive part of the individual or family budget, even if affordable overall. Clearly, the first type of need is concentrated among those on a low income, whereas the second type may be more prevalent among middle-income groups. Accordingly, we expect that evaluating the need criterion for the beneficiaries of eco-social policies will be strongly influenced by individuals' own socio-economic position. For example, most people with a middle income will be likely to believe that they are in greater need of state support, because in absolute terms their extra costs will greatly exceed those of low-income groups. A practical implication of this is that if an eco-social measure is targeted too narrowly at low-income groups, it will be perceived as unfair through ignoring people with greater means but with much higher climate change-related expenses.

The issue of different types of needs and how individuals assess them is closely linked to the control criterion, because the deservingness heuristic 'prompts individuals to oppose welfare benefits when need reflects a lack of motivation (i.e. "laziness") but support benefits when the need is caused by random events beyond the individual's control (i.e. "bad luck")' (Jensen \& Petersen 2017 p. 71). Traditional social risks to some extent allow the question of whether benefit recipients are or were responsible for their situation of neediness. For example, could they have taken a low paid and less pleasant job or have invested more time in vocational 
training? However, it is much more difficult to hold individuals responsible for living in areas that are more polluted or more exposed to floods, for not being able to finance the installation of solar panels or to afford retro-fitting a house to save energy, or for being unable to use public transport, cycle or run a more fuel-efficient car when commuting to work.

Reciprocity affects deservingness perceptions in the sense that people are more inclined to support benefits for individuals who are perceived as having contributed before the social risk occurred, or intend to do so in exchange for their benefit. For example, elderly people deserve pensions because they have paid taxes and social insurance contributions during their working life. With regard to ecological risks, a strong case can be made for 'negative reciprocity', as on average, those on a low income have contributed far less than others to air pollution and global warming (Gough 2013; Pye et al. 2008). Nevertheless, it is questionable to what extent the wider public is aware of the income group differences in carbon footprints. This makes it desirable that where possible, eco-social measures entail some conditionalities of engaging in additional eco-friendly behaviour; for example by using public transport, recycling, planting trees, cycling or switching to LED bulbs. Alongside demonstrating reciprocity, eco-friendly behaviour can also signal a positive and grateful attitude, which is another important determinant of welfare deservingness.

As in the case of traditional welfare benefits, the perceived deservingness of the target groups for eco-social measures will also depend on (perceived) social distance from the rest of society. This in turn will be contingent on the specific types of risk that various eco-social measures aim to address. When the risks are concentrated in disadvantaged areas (for example air pollution in low-income neighbourhoods populated mostly by ethnic minorities), the general public may not feel a strong sense of shared identity with the beneficiaries and therefore may consider them less deserving. By contrast, when an ecological hazard threatens 
a group that closely resembles mainstream society (for example flooding in a coastal area populated by the majority ethnic group), the perceived deservingness will be higher. Again, one practical implication is that in order to be perceived as designed to help well-deserving groups, eco-social measures should not be too narrowly targeted.

In addition to the five criteria above, there is also a need to consider compensation as an additional deservingness criterion with regard to the beneficiaries of eco-social policies. Somewhat surprisingly, welfare deservingness literature has paid little attention to this criterion, even though the welfare state has been argued to be partly a compensation for the negative side effects of the market economy (see e.g. Offe, 1984). Moreover, advanced welfare states do provide and mandate compensatory benefits, such as workplace injury compensation, vocational retraining, severance pay and other support for workers displaced by economic restructuring or the like.

The importance of compensatory measures is also highlighted in the present context of the COVID-19 pandemic. Following the national lockdowns to contain the spread of the virus, European governments have felt obliged to provide relatively generous benefits - often without proof of neediness - in order to compensate individuals and small enterprises for the loss of income. This is even the case for right-wing governments in liberal welfare states, such as the UK. We therefore perceive compensation as an important criterion that may enhance public support for eco-social policies. However, we also stress that the public framing of eco-social policies will be crucial. When eco-social measures are portrayed as being intended to compensate for damage inflicted by society, beneficiaries will be viewed as highly deserving. However, if eco-social benefits are presented as compensation for a low income that deters people from coping with the challenges of climate change and associated policies, existing stereotypes are very likely to play an important role, potentially making the 
beneficiaries of eco-social policies appear as little deserving as those receiving social assistance.

\section{Discussion and conclusion}

As global warming continues unabated and its threats intensify, the need for large-scale ecosocial policies becomes more and more pressing. While not necessarily the most decisive aspect, public opinion is likely to play a significant role in shaping the ambition of governments' eco-social agendas. Nevertheless, there are currently both theoretical and empirical gaps in scientific knowledge about public attitudes towards eco-social policies. Aiming to contribute to narrowing these gaps, in the present article we have sought to outline a general comparative theoretical framework that can help us understand the potential cleavages in attitudes towards eco-social policies. Figure 1 provides a graphical illustration of this framework.

We have argued that at the contextual level, at least two sets of factors are important: structural and institutional. We anticipate that due to affordability issues, support for ecosocial measures will be higher in more affluent countries. The objective need for such policies will also play a role, in that the public will be more receptive of eco-social policies in countries that are more exposed to the effects of global warming, and those where inequality and poverty are higher. Further, the effect of the existing welfare states' institutional setup will be contingent on the design of specific eco-social policies; that is, the extent to which they align with or deviate from the dominant principle of distributive justice and the customary scope of state intervention. In this regard, we hypothesise that because eco-social policies are - as we define them - vertically redistributive, their promotion will be more challenging 
in welfare states that are built around the social insurance principle and where state intervention in welfare provision is less extensive.

At the individual level, the endorsement of eco-social measures by low-income groups necessitates that the policies complement rather than substitute for existing welfare benefits and that public awareness of the highly unequal social effects of environmental problems is increased. Nevertheless, we expect workers employed in fossil fuel industries to be among the primary opponents of most effective environmental measures, such as carbon taxes, unless substantial eco-social programmes are urgently put in place to compensate for the loss of jobs and incomes. We also expect that large-scale eco-social policies will further deepen the ideological polarisation, though this may be partially mitigated if right-wing political parties endorse and promote the eco-social policy agendas.

With regard to the welfare deservingness criteria, we have argued that the beneficiaries of eco-social policies will score favourably on the control criterion, as environmental problems are clearly beyond any individual's control. Their perceived deservingness will also increase if eco-social measures are presented to the general public as compensating for the damage inflicted by society. However, we have also warned that if these measures are portrayed as compensation for the inability of low-income groups to cope with the eco-social risks, the perceived deservingness will be low. In relation to the other welfare deservingness criteria, the composition and the size of the target group will matter. For example, the needs of lowincome groups may be considered as less pressing if the environmental risk imposes much higher expenditure on middle-income groups. In addition, the general public is less likely to feel a strong affiliation with the beneficiaries of narrowly targeted policies. One way of ensuring beneficiaries are highly deserving of welfare is thus for eco-social policies to cover not only low-income, but also middle-income groups. Another way of improving beneficiaries' 
perceived welfare deservingness is to attach some conditionalities requiring engagement in eco-friendly behaviour, as this can enhance reciprocity and indicate positive attitudes.

While our framework provides an essential starting point for the comparative analysis of attitudes towards eco-social policies, we are aware that we have only scratched the surface. More theorising is needed in order to gain a full grasp of the mechanisms that shape these opinions. For example, at both the contextual and the individual level, we focused only on the major determinants conventionally used in welfare attitudes research. However, this does not preclude the possibility of other factors also having an effect at both levels. These may include countries' reliance on the import and export of fossil fuels, prevailing media discourses and the strength of ecological movements and green parties, as well as the perceived success of existing ecological policies, trust in public institutions, satisfaction with public services and post-materialist cultural values. In addition, it is very likely that the discussed factors interact. For example, a country's greater exposure to risks stemming from climate change may weaken the ideological polarisation concerning eco-social policies.

Figure 1. Determinants of public support for eco-social policies: A comparative theoretical framework

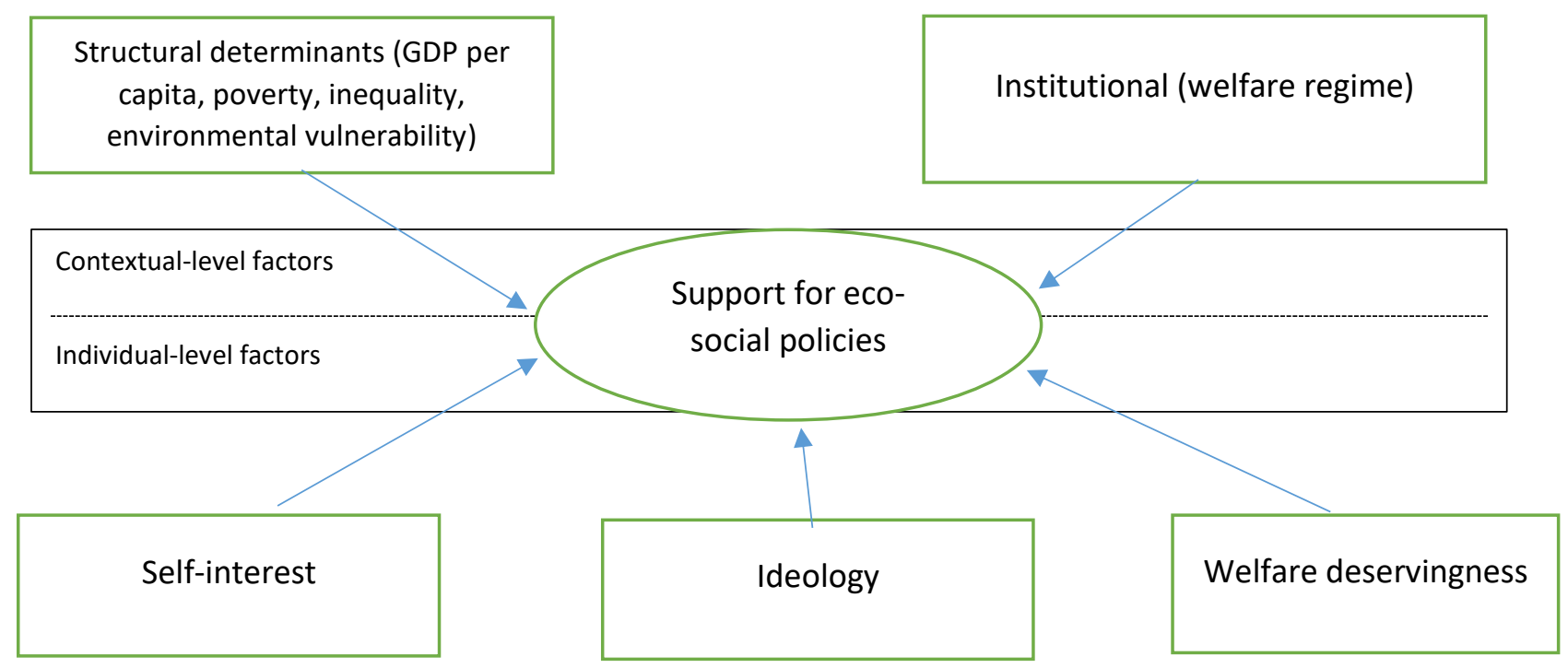


Addressing these issues, as well as testing our theoretical framework, will require systematic research using various methodological approaches. Given that eco-social policies are currently very limited in their scope and most people are likely to be unfamiliar with the term itself, two distinct methods may be particularly promising at the initial stage. The first is a traditional qualitative research method: focus groups. The advantage of this approach is that it allows researchers to explain the concept of eco-social policies in sufficient detail to study participants and also to respond to their questions about the technical aspects of these measures throughout discussions. The second is a quantitative approach: vignette experiments. These are less frequently applied in welfare opinion research, but are particularly useful for analysing attitudes towards prospective policies. In these studies, respondents are presented with descriptions (vignettes) of hypothetical, though usually realistic policy scenarios in which both the policy design and the characteristics of the target group are randomly varied across respondents. Each respondent is required to read several of these vignettes and to rate the respective policy scenarios. In this way, it is possible to examine whether and how the experimental manipulations of the attributes and objectives of a particular eco-social policy affect the extent of its support, how different dimensions of such policies interact with target groups' hypothetical background characteristics, and whether some sociodemographic or ideological groups react more strongly to certain aspects of eco-social policies and/or their beneficiaries. The insights derived from focus groups and vignette experiments in turn could guide the development of survey modules to be incorporated into large-scale cross-national surveys. 


\section{References}

Blekesaune, M. (2007). Economic conditions and public attitudes to welfare policies. European Sociological Review, 23(3), 393-403.

Blekesaune, M., \& Quadagno, J. (2003). Public Attitudes toward Welfare State Policies: A Comparative Analysis of 24 Nations. European Sociological Review, 19(5), 415-427.

Boas, I., Farbotko, C., Adams, H., Hulme, M. (2019). Climate migration myths. Nature Climate Change, 9(12), 901-903.

Bohnenberger, K., \& Koch, M. (2020). Making welfare resilient: Creating stable and sustainable welfare systems in times of declining economic growth (No. 2).

Bonoli, G. (2005). The politics of the new social policies: providing coverage against new social risks in mature welfare states. Policy \& Politics, 33(3), 431-449.

Bonoli, G. (2007). Time Matters: Postindustrialization, New Social Risks, and Welfare State Adaptation in Advanced Industrial Democracies. Comparative Political Studies, 40(5), 495-520.

Brechin, S., \& Kempton, W. (1994). Global environmentalism: a challenge to the postmaterialism thesis? Social Science Quarterly, pp. 245-269.

Büchs, M., Bardsley, N., \& Duwe, S. (2011). Who bears the brunt? Distributional effects of climate change mitigation policies. Critical Social Policy, 31(2), 285-307.

Büchs, M., \& Koch, M. (2017). Postgrowth and Wellbeing: Challenges to Sustainable Welfare, Cham: Plagrave Macmillan. doi:10.1007/978-3-319-59903-8

Busemeyer, M. R., \& Neimanns, E. (2017). Conflictive preferences towards social investments and transfers in mature welfare states: The cases of unemployment benefits and childcare provision. Journal of European Social Policy, 27(3), 229-246.

Carlsson, F., Kataria, M., Krupnick, A., ... Sterner, T. (2010). Paying for Mitigation: A Multiple Country Case Study. Retrieved from https://www.rff.org/publications/workingpapers/paying-for-mitigation-a-multiple-country-study-1/

Chaisty, P., \& Whitefield, S. (2015). Attitudes towards the environment: are post-Communist societies (still) different? Environmental Politics, 24(4), 598-616.

Chomsky, N., \& Pollin, R. (2020). Climate Crisis and the Global Green New Deal: The Political Economy of Saving the Planet, London: Verso.

Dallinger, U. (2010). Public support for redistribution: What explains cross-national differences? Journal of European Social Policy, 20(4), 333-349.

Degryse, C., \& Pochet, P. (2009). Paradigm shift: social justice as a prerequisite for sustainable development (No. 2), Brussels.

Diekmann, A., \& Franzen, A. (1999). The wealth of nations and environmental concern. Environment and Behavior, 31(4), 540-549.

Dunlap, R. E., \& Mertig, A. G. (1995). Global concern for the environment: is affluence a prerequisite? Journal of Social Issues, 51(4), 121-137.

Esping-Andersen, G. (1990). The three worlds of welfare capitalism, Cambridge: Polity press. 
Fairbrother, M. (2013). Rich people, poor people, and environmental concern: Evidence across nations and time. European Sociological Review, 29(5), 910-922.

Finseraas, H. (2009). Income inequality and demand for redistribution: A multilevel analysis of european public opinion. Scandinavian Political Studies, 32(1), 94-119.

Fitzpatrick, T. (2011). Challenges for social policy. In T. Fitzpatrick, ed., Understanding the environment and social policy, Bristol, UK: Policy Press.

Fraile, M., \& Ferrer, M. (2005). Explaining the Determinants of Public Support for Cuts in Unemployment Benefits Spending across OECD Countries. International Sociology, 20(4), 459-481.

Franzen, A., \& Meyer, R. (2010). Environmental attitudes in cross-national perspective: A multilevel analysis of the ISSP 1993 and 2000. European Sociological Review, 26(2), 219-234.

Fritz, M., \& Koch, M. (2019). Public Support for Sustainable Welfare Compared: Links between Attitudes towards Climate and Welfare Policies. Sustainability, 11(15), 4146.

Gelissen, J. (2007). Explaining Popular Support for Environmental Protection: A Multilevel Analysis of 50 Nations. Environment And Behavior, 39(3), 392-415.

Gerhards, J., \& Lengfeld, H. (2008). Support for European union environmental policy by citizens of EU-member and accession states. Comparative Sociology, 7(2), 215-241.

Gough, I. (2013). Carbon Mitigation Policies, Distributional Dilemmas and Social Policies. Journal of Social Policy, 42(2), 191-213.

Gough, I. (2017). Heat, greed and human need. Climate change, capitalism and sustainable wellbeing, Cheltenham, UK: Edward Elgar.

Gough, I., Meadowcroft, J., Dryzek, J., Ortiz, R. (2008). JESP symposium: Climate change and social policy. Journal of European Social Policy, 18(4), 325-344.

Gugushvili, D. (2021). Economic Growth vs. Environmental Sustainability Dilemma: What does the European Public Support? International Journal of Comparative Sociology.

Harring, N. (2013). Understanding the effects of corruption and political trust on willingness to make economic sacrifices for environmental protection in a cross-national perspective. Social Science Quarterly, 94(3), 660-671.

Hasenfeld, Y., \& Rafferty, J. A. (1989). The determinants of public attitudes toward the welfare state. Social Forces, 67(4), 1027-1048.

IPCC. (2014). Climate change 2014: Impacts, adaptation, and vulnerability. Part A: Global and sectoral aspects. Contribution of the Working Group II to the fifth assessment report of the Intergovernmental Panel on Climate Change, New York and Cambridge.

Jaeger, M. M. (2013). The effect of macroeconomic and social conditions on the demand for redistribution: A pseudo panel approach. Journal of European Social Policy, 23(2), 149163.

Jæger, M. M. (2006). What makes people support public responsibility for welfare provision: Self-interest or political ideology? A longitudinal approach. Acta Sociologica, 49(3), 321-338.

Jakobsson, N., Muttarak, R., \& Schoyen, M. A. (2018). Dividing the pie in the eco-social state: Exploring the relationship between public support for environmental and welfare policies. Environment and Planning C: Politics and Space, 36(2), 313-339.

Jensen, C., \& Petersen, M. B. (2017). The Deservingness Heuristic and the Politics of Health Care. American Journal of Political Science, 61(1), 68-83.

Kallis, G. (2011). In defence of degrowth. Ecological Economics, 70(5), 873-880.

Koch, M., \& Fritz, M. (2014). Building the Eco-social State: Do Welfare Regimes Matter? 
Journal of Social Policy, 43(4), 679-703.

Koch, M., \& Mont, O. (Eds.). (2016). Sustainability and the political economy of welfare, London and New York: Routledge.

Kvaløy, B., Finseraas, H., \& Listhaug, O. (2012). The publics' concern for global warming: A cross-national study of 47 countries. Journal of Peace Research, 49(1), 11-22.

Markkanen, S., \& Anger-Kraavi, A. (2019). Social impacts of climate change mitigation policies and their implications for inequality. Climate Policy, 19(7), 827-844.

Marquart-Pyatt, S. T. (2012). Contextual influences on environmental concerns crossnationally: A multilevel investigation. Social Science Research, 41(5), 1085-1099.

Martin, S. (2010). Climate Change, Migration, and Governance. Global Governance, 16(3), 397-414.

Mccright, A. M., \& Dunlap, R. E. (2011). The Politicization Of Climate Change And Polarization In The American Public's Views Of Global Warming, 2001-2010. Sociological Quarterly, 52(2), 155-194.

McCright, A. M., Dunlap, R. E., \& Marquart-Pyatt, S. T. (2016). Political ideology and views about climate change in the European Union. Environmental Politics, 25(2), 338-358.

Meltzer, A. H., \& Richard, S. F. (1981). A Rational Theory of the Size of Government. Journal of Political Economy, 89(5), 914-927.

Murray, C. A. (1984). Losing Ground: American Social Policy, 1950-1980, New York: Basic Books.

Offe, C. (1984). Contradictions of the Welfare State, London: Hutchinson.

Opitz Stapleton, S., Nadin, R., Watson, C., \& Kellett, J. (2017). Climate change, migration and displacement. The need for a risk-informed and coherent approach, London and New York.

Otto, A., \& Gugushvili, D. (2020). Eco-Social Divides in Europe: Public Attitudes towards Welfare and Climate Change Policies. Sustainability, 12(1), 404.

Poortinga, W., Whitmarsh, L., Steg, L., Böhm, G., \& Fisher, S. (2019). Climate change perceptions and their individual-level determinants: A cross-European analysis. Global Environmental Change, 55(February), 25-35.

Pye, S., Skinner, I., Meyer-Ohlendorf, N., Leipprand, A., Lucas, K., \& Salmons, R. (2008). Addressing the social dimensions of environmental policy. A study on the linkages between environmental and social sustainability in Europe, Brussels.

Roosma, F., Van Oorschot, W., \& Gelissen, J. (2016). The Achilles' Heel of Welfare State Legitimacy: Perceptions of Overuse and Underuse of Social Benefits in Europe. Journal of European Public Policy, 23(2), 177-196.

Schaffrin, A. (2013). Who pays for climate mitigation? An empirical investigation on the distributional effects of climate policy in the housing sector. Energy and Buildings, 59, 265-272.

Schaffrin, A. (2014). The new social risks and opportunities of climate change. In T. Fitzpatrick, ed., International Handbook on Social Policy and the Environment, Cheltenham, UK: Edward Elgar, pp. 3-61.

Schneider, F., Kallis, G., \& Martinez-Alier, J. (2010). Crisis or opportunity? Economic degrowth for social equity and ecological sustainability. Introduction to this special issue. Journal of Cleaner Production, 18(6), 511-518.

Serret, Y., \& Johnstone, N. (Eds.). (2006). The Distributional Effects of Environmental Policy, Cheltenham, UK: Edward Elgar.

Söderholm, P., \& Pettersson, F. (2008). Climate policy and the social cost of power 
generation: Impacts of the Swedish national emissions target. Energy Policy, 36(11), 4154-4158.

Svallfors, S. (1997). Worlds of Welfare and Attitudes to Redistribution: A Comparison of Eight Western Nations. European Sociological Review, 13(3), 283-304.

Taylor-Gooby, P. (2004). New Risk, New Welfare: The Transformation of the European Welfare State, Oxford: Oxford University Press.

Tjernström, E., \& Tietenberg, T. (2008). Do differences in attitudes explain differences in national climate change policies? Ecological Economics, 65(2), 315-324.

van Oorschot, W. (2006). Making the difference in social Europe: deservingness perceptions among citizens of European welfare states. Journal of European Social Policy, 16(1), 2342.

van Oorschot, W., \& Roosma, F. (2017). The Social Legitimacy of Targeted Welfare and Welfare Deservingness. In W. van Oorschot, F. Roosma, B. Meuleman, \& T. Reeskens, eds., The Social Legitimacy of Targeted Welfare: Attidues to Welfare Deservingness, Cheltenham: Edward Elgar, pp. 3-36.

Zachmann, G., Fredirksson, G., \& Claeys, G. (2018). Distributional effects of climate policies (No. 28), Brussels. 